\title{
PLANTAS MEDICINAIS NO TRATAMENTO DAS ENFERMIDADES FEMININAS, NA OBRA “DESENGANOS PARA A MEDICINA” DE GABRIEL GRISLEY (1656)
}

\author{
MEDICINAL PLANTS IN THE TREATMENT OF FEMININE DISEASES, IN THE \\ BOOK OF GABRIEL GRISLEY "DESENGANOS PARA A MEDICINA" (1656)
}

\begin{abstract}
Resumo
É objetivo do presente trabalho apresentar as plantas medicinais usadas no tratamento das enfermidades femininas na obra do médico alemão Gabriel Grisley, com os tratamentos e indicações do autor, bem como suas identificações botânicas. Muitas dessas plantas, vindas da Europa, tem amplo uso atual na fitoterapia popular brasileira. Apresentamos também um histórico sobre as concepções médicas centradas nas alterações do útero, chamado na época de "matriz" ou "madre", que segundo os autores médicos da época, seria o órgão responsável pela maior parte dos problemas reprodutivos e da sexualidade das mulheres, abordados com profundo caráter misógino, desde a antiguidade até o século XVII, bem como é apresentada uma análise sobre o protagonismo da mulheres como fundadoras das atividades agrícolas e no seu conhecimento sobre as plantas na pré-história.
\end{abstract}

Palavras-chave: Plantas medicinais. Enfermidades femininas. Úterocentrismo. Misoginia.

\begin{abstract}
The objective of the present work is to present the medicinal plants used in the treatment of female diseases in the work of the German physician Gabriel Grisley, with the treatments and indications of the author, as well as their botanical identifications. Many of these plants, coming from Europe, have wide current use in Brazilian popular herbal medicine. We also present a history of the medical conceptions centered on the alterations of the uterus, called in the "matrix" or "madre" era, which, according to the medical authors of the time, would be responsible for most of the reproductive problems and sexuality of women, addressed with a deep misogynist character, from antiquity to the seventeenth century, As well as an analysis of the role of women as founders of agricultural activities and their knowledge of plants in prehistory.
\end{abstract}

Keywords: Medicinal plants. Female diseases. Uterocentrism. Misogyny. 
A obra do médico alemão Gabriel Grisley intitulada Desenganos para a Medicina (1656), referese a flora medicinal portuguesa. Uma outra obra do mesmo autor Viridarium Lusitanicum (1661), a qual é considerada a primeira lista das plantas de Portugal. Tendo-se estabelecido em Portugal no tempo do rei D. João IV, Grisley foi encarregado pelo monarca de organizar um horto botânico em Xabregas (localidade próxima a Lisboa).

Baseado em Dioscórides, Plínio, Galeno e Laguna, bem como nos seus próprios conhecimentos e na experiência adquirida no cultivo de uma horta medicinal doada por D. João IV para que "ordenou S. M. que Deus guarde, se plantassem em uma horta todas as ervas medicinaes, para instrucção dos que por officio estão obrigados em conhecellas" (Grisley,1656: 3).

Sua obra tinha como objetivo central corrigir os enganos (daí o título de "desenganos") no uso da plantas medicinais, além de divulgar as plantas que eram encontradas no horto organizado por ele (daí porque os capítulos da sua obra são denominados "canteiros").

Assim, o autor na sua obra recomenda diversas plantas medicinais, com suas denominações latinas, preparações e aplicações, como remédios para diversas doenças e problemas humanos e até de animais domésticos.

Como destaque especial constam da sua obra plantas medicinais indicadas especificamente nas doenças e problemas ligados à função reprodutiva das mulheres.

Como escreve o historiador Henrique Carneiro: "O estudo dos herbários dos séculos XVI ao XVIII fornece um conjunto de fontes preciosas para diversos domínios da pesquisa histórica, notadamente para a história da botânica e da medicina" (Carneiro, 2002: 15).

Com essa perspectiva histórica, é objetivo do presente trabalho apresentar essas plantas medicinais, os tratamentos e indicações do autor, bem como suas identificações botânicas. Muitas das quais, com amplo uso na fitoterapia popular brasileira.

\section{Aspectos históricos sobre as concepções médicas sobre o corpo feminino}

$\mathrm{Na}$ medicina medieval, a tradição médica antiga ocidental e árabe, compreendia a mulher $\mathrm{e} o$ seu corpo a partir de três eixos norteadores: fisiologia/ anatomia, reprodução e enfermidades (úterocentrismo). Sendo a função reprodutiva o eixo explicativo central, estas tradições apresentavam o corpo feminino como um organismo complexo e interligado, destinado exclusivamente a procriação. Nesta perspectiva, órgãos e/ ou funções relacionados à concepção, como útero, mamas e o fluxo menstrual, ganharam papel de destaque (Souza, 2012: 130).

No campo das enfermidades, a associação entre mulher, corpo e reprodução reforçou concepções de caráter úterocentristas, segundo as quais todos os problemas e afecções femininas estariam relacionados direta ou indiretamente ao útero; assim justifica-se a grande presença de prescrições destinadas a cuidar e a curar problemas relacionados aos seios (mamas) e ao fluxo menstrual. O útero (madre) figura como um órgão causador de males e enfermidades. A ideia de deslocamento do útero pelo interior do corpo e sua possível fixação na cabeça, predomina na maioria das receitas. Assim, apresenta-se comum a prescrição de substâncias mal cheirosas nas partes superiores do corpo para provocar a descida da madre, e/ou ervas aromáticas nas partes pudendas com a intenção de atraí-la e provocar sua descida (Souza, 2012: 134).

Os hipocráticos chamavam a atenção para mobilidade do útero no corpo da mulher; pensavam que este podia descolar-se para outras partes do corpo e unirse a outros órgãos como o coração, o fígado, o cérebro, entre outros. Diziam que este movimento era causado pela sua secura, produzida pela falta de relações sexuais, por isso, era atraído como um imã a outros órgãos mais úmidos. Essas afirmações sobre o útero, evidenciam que tal "explicação científica", não só medicalizou o corpo da mulher, medicalizou também a sua sexualidade e seu desejo e, como consequência, deveria ser um assunto de intervenção dos médicos (Camacaro Gómez, 2007: 28 ).

Uma vez que o útero seria um órgão passível de ser controlado, passou a ser de interesse da ciência médica, sendo a razão de ser da patologia feminina. Então, o uterocentrismo, serviu para justificar a enfermidade feminina por excelência, a histeria, que se origina do termo grego hystera (útero ou matriz), da antiga medicina grega e desde então tradicionalmente se considerava a histeria como uma enfermidade do útero. $\mathrm{O}$ estudo da histeria ocupou grande parte dos trabalhos de Hipócrates 
e Galeno, que mais tarde concluiu que a histeria era uma enfermidade relacionada com a falta de prazer sexual (Camacaro Gómez, 2007: 27).

Para a teoria hipocrática a enfermidade denominada de "sufocação da madre" ( causada pelos deslocamentos do útero) poderia ser uma consequência desagradável da castidade, causada pela retenção do "esperma" feminino, a menstruação na concepção aristotélica. Em função disso, os médicos prescreviam as relações sexuais como práticas benéficas para a saúde corporal masculina e feminina. No caso feminino, o coito torna-se também uma forma capaz de amenizar e equilibrar a frialdade do organismo feminino. Na impossibilidade dos intercursos, recomendam a masturbação para expelir os fluídos femininos que estavam retidos e que ocasionam a enfermidade. As práticas masturbatórias eram realizadas pelas parteiras ou pelas próprias pacientes, uma vez que os médicos não podiam tocar o corpo das mulheres, devido ao tabu do corpo feminino (Santos, 2013: 16).

No seu deslocamento, se o útero ia para o fígado, a mulher perdia imediatamente a voz, passava a ranger os dentes e sua pele ficava escura. Se o útero ia para a cabeça, a mulher sentia dores nas narinas e abaixo dos olhos. Se o movimento se dava em direção às pernas, a mulher tinha espasmos sob as unhas dos dedões dos pés. Se o útero andava rumo ao coração ou às vísceras, o quadro poderia ser ainda mais grave, provocando o sufocamento (Stigger, 2015, p.12).

\section{Escreve a historiadora Mary Del Priore:}

A madre, que se erigia como altar de procriação e templo de fertilidade, era recorrentemente atacada por enfermidades mal diagnosticadas, transformando o corpo da mulher num campo de batalha entre o médico e a enfermidade desconhecida. Clísteres, sangramentos e purgativos raramente a aliviavam. Se ela tinha suas feridas mundificadas por receitas ancilares e se a botica doméstica à base de ervas e raízes era o seu paliativo, não há relatos exatos ou diretos dessa antropologia vegetal relacionada à intimidade feminina [...] Tanto na mentalidade de médicos quanto na de mulheres, os costumeiros "males da madre" atraíam e inquietavam, pois o mesmo espaço que tinha o poder de transformar sementes em seres vivos era, simultaneamente, cloaca para expelir e excretar o considerado "imundo" sangue das purgações mensais. O homem nascia, portanto, de um esgoto úmido e escuro, e tal concepção reforçava uma ideia que surgira com Aristóteles e que se difundira com a Igreja: a madre era ao mesmo tempo território de utilidade e abjeção (Del Priore, 1993: 212).

Grande parte da tradição médica antiga e árabe, especialmente as representações construídas sobre as mulheres e o corpo feminino, foi incorporada e difundida literatura medica do século XIII. Neste sentido, a mulher continuou a ser representada a partir do seu corpo; e seu corpo, compreendido como incompleto e imperfeito, permaneceu associado à reprodução (Souza, 2012: 130131).

Na obra De secretis mulierium de Pseudo Alberto Magno, no capítulo XI intitulado, "Sobre o defeito do útero", o autor descreve a "sufocação da madre", baseando suas afirmações nas autoridades médicas em geral, citando especificamente Galeno, como referência ao tema. Identifica ainda como principal causa do deslocamento do útero pelo corpo até o coração a retenção da menstruação, em função da frialdade feminina, que para a saúde corporal deveria ser expelida:

A sufocação, de acordo com as autoridades médicas, é a compressão dos espíritos vitais que saíram do corpo por causa de um defeito do útero, resultando na dificuldade de respirar. Isto acontece quando o útero sai do seu lugar próprio: isso resulta na frieza do coração que provoca na mulher uma síncope, isto é, uma fraqueza do coração e isso é, muitas vezes, acompanhado pela tontura na cabeça (Pseudo Alberto apud Santos, 2013: 12).

[...] Esta enfermidade acontece nas mulheres porque elas estão repletas da menstruação corrupta e venenosa e é bom para elas, sejam jovens ou velhas, que essa matéria possa ser expelida. Por isso, é prudente e bom que essas mulheres, não importam se são jovens ou velhas, sirvamse amiúde dos homens para expulsar a dita matéria. Convém muito às jovens que têm abundancia da matéria úmida.[...] Estas jovens, quando possuem dita materia em abundancia, senten grandes desejos de praticar o coito por causa dessa abundancia. Isso é instintivo da natureza. Por isso, 
é pecado contra a natureza separá-las e proibir-lhes o acesso ao aquilo que desejam, ainda que seja um pecado contra os bons costumes, sobre o qual nada temos a dizer. (Pseudo Alberto apud Santos, 2013: 12).

O trecho revela, assim, as tensões entre o pensamento médico laico e o religioso: o primeiro, busca compreender o funcionamento dos corpos na perspectiva da natureza e propor outra visão da sexualidade humana vinculada à preservação da saúde; já o pensamento religioso, normatizador, caracterizava-se por ser mais restritivo em relação a ela, e por isso o autor faz a ressalva de que sua prescrição vai contra os costumes da sociedade da época (Santos, 2013: 13).

Segundo Del Priore (1999), os médicos portugueses, alheios, em sua grande maioria, às descobertas científicas que começavam a se delinear no restante da Europa a partir do século XVII, limitavamse a repetir os chamados "antigos" (Aristóteles, Plínio, Dioscórides, Galeno, Alberto, o Grande). Herdeiros da tradição medieval, tais doutores insistiam em sublinhar a função reprodutiva da madre, excluindo o que não tivesse finalidade procriativa.

Citando médicos portugueses da época, Del Priore (1999), cita por exemplo, Bernardo Pereira que escreveu que a madre era capaz de deslocar-se no interior do corpo da mulher, subindo até a sua garganta e causando-lhe asfixia. Quando não se movimentava, emitia vapores ou "fumos" capazes de infectar "o cérebro, o coração, o fígado, o cepto transverso" por meio de "humores viciosos que, detidos no útero" apodreciam, adquirindo má qualidade". Acreditava-se, ainda, que a madre se alimentava de sangue e "pneuma", e que o espírito vital, emitido pelo homem e encarregado da fecundação, chegava-lhe através de uma grande artéria que desceria do coração ao longo da coluna vertebral (Del Priore, 1999: 179).

No processo de fecundação, a fêmea era um elemento passivo. Comparada por alguns médicos às galinhas, tinham por exclusiva função portar os "ovos". Mas por que seriam as mulheres incapazes de procriar, cabendo-lhes apenas a tarefa de carregar e fazer amadurecer o fruto, numa analogia com a natureza? Invocando Aristóteles, o médico Francisco da Fonseca Henriques dizia que elas não tinham "matéria seminal prolífica" e tão somente concorriam para a geração com o "sangue mênstruo" que alimentava a criança. "A mulher, dizia, é um animal imperfeito e passivo, sem princípio e vigor eficiente, razão porque os bárbaros the chamam animal acessório". Entendia-se que para cumprir sua função de portadora de "ovos", a madre tinha dois orifícios: um exterior, chamado de collum matricis, no qual o coito se realizava, outro, interior, os matricis. Este, segundo Hipócrates, fechava-se na sétima hora seguida à concepção (tão hermeticamente quanto uma "bolsa") e nem a ponta de uma agulha poderia penetrá-lo (Del Priore, 1999: 180).

Segundo esta mesma tradição, a madre era fria e seca (prova de sua inferioridade face ao membro masculino, quente e úmido), provida de pilosidades internas (as masculinas, externas) e dotada de sete compartimentos distintos. Três à direita onde se engendravam meninos, três à esquerda onde cresciam meninas, e um no centro, reservado aos hermafroditas. Uma das características da madre era a sua capacidade de amar apaixonadamente alguma coisa e de aproximar-se do membro masculino por um movimento precipitado, para dele extrair de que buscar o seu prazer. Porém, o aspecto mais tocante de sua personalidade era, segundo um médico, "o desejo inacreditável de conceber e procriar" (Del Priore, 1999: 180).

Como salienta a mesma autora, com tais concepções,

A medicina traduzia então as poucas descobertas sobre a natureza feminina em juízos fortemente misóginos e desconfiados em relação às funções do corpo da mulher. $\mathrm{Na}$ tentativa de isolar os fins aos quais a natureza feminina devia obedecer, os médicos reforçavam tão somente a ideia de que o estatuto biológico da mulher (parir e procriar) estaria ligado a um outro, moral e metafísico: ser mãe, frágil e submissa, ter bons sentimentos, etc. Convém notar que a valorização da madre como órgão reprodutor levava a uma valorização da sexualidade feminina, mas não no sentido de sua realização e sim no e sua disciplina [...] $\mathrm{O}$ desconhecimento anatômico, a ignorância fisiológica e as fantasias sobre o corpo feminino, acabavam abrindo espaço para que a ciência médica construísse um saber masculino e um discurso de desconfiança em relação à mulher (Del Priore, 2004: 83-84). 
O processo histórico de medicalização do corpo feminino passa, necessariamente, pela ideia de que existe uma natureza biológica determinante e dominante da condição feminina. É justamente por meio dessa concepção que a medicina poderá se apropriar do corpo das mulheres (Vieira, 2002: 68).

A ideia de natureza feminina baseia-se em fatos biológicos que ocorrem no corpo da mulher - a capacidade de gestar, parir e amamentar. Na medida em que essa determinação biológica parece justificar plenamente as questões sociais que envolvem este corpo é que ela passa a ser dominante, como explicação legítima e única sobre estes fenômenos (Vieira, 2002: 68).

Daí decorrem ideias sobre a maternidade, instinto maternal e divisão sexual do trabalho como atributos "naturais c essenciais" à divisão de gênero na sociedade. A natureza feminina faz parte do conjunto de concepções pelas quais a identidade de gênero e suas implicações são construídas na sociedade e na cultura (Vieira, 2002: 68).

A crença naturalista estabelece uma relação de causalidade lógica entre o potencial biológico da mulher de gerar filhos e o cuidado c criação das crianças como atividade feminina. A mística maternal estabelece o potencial para a maternidade como fato fundamental para a constituição da feminilidade e identidade da mulher. A maternidade, ou melhor, a "natureza maternal", seria, então, um fator nuclear do qual decorreria uma série de atributos de personalidade e conduta da mulher que the seriam "naturais", negando-se persistentemente as intermediações da cultura neste âmbito. As concepções que se constroem sobre a natureza feminina impõem, para o saber médico, esforços consideráveis para desenvolver o conhecimento sobre as especificidades biológicas da condição feminina, como pressuposto do movimento maior de transformação social que ocorreu a partir do século XVIII, mudando a relação da prática médica com o corpo feminino (Bonder, 1984 apud Vieira, 2002: 68).

A medicalização do corpo feminino se estabelece no século XIX, em meio aos discursos de exaltação da maternidade. No entanto, esse processo teve início trezentos anos antes da institucionalização do parto como evento hospitalar e do estabelecimento da obstetrícia como disciplina médica (Vieira, 2002: 70).

Na Idade Média, as mulheres que se dedicavam a essas atividades, eram geralmente mais velhas, muitas vezes identificadas como vetula sortilega, conhecidas como curandeiras e parteiras. Geralmente não tinham acesso à cultura letrada; assim, a aquisição de suas habilidades se dava por meio da observação das colegas mais velhas em ação e da própria experiência. A transmissão desses saberes empíricos, de práticas, e dos efeitos curativos das ervas era feita oralmente, e na maior parte das vezes de geração a geração (Santos, 2013: 8).

Por um longo período, partejar foi uma tradição exclusiva de mulheres. A partir do século XVI, essa tradição começa a sofrer regulamentações, governamentais ou da igreja, submetendo as parteiras das cidades europeias a exames prestados diante de comissões municipais ou eclesiásticas. O ponto fundamental dessa regulação relaciona-se à garantia do estado emergente e da igreja de que não seriam realizados abortos e infanticídios. Exigiase da parteira examinada pelas comissões a profissão da fé cristã, o saber batizar o recém-nato moribundo, e moral e reputação ilibadas. Essas regulamentações coincidiram com o processo de perseguição das feiticeiras - entre elas, muitas parteiras (Mello, 1983 apud Vieira, 2002: 70).

A caça às bruxas e a extinção das curandeiras e parteiras fazem parte da história de exclusão das mulheres da prática médica como estratégia do Estado e da Igreja para monopolizar o saber acerca da cura das doenças, e legitimá-lo por meio das universidades criadas no Renascimento. Ao tornar-se uma profissão alicerçada pela autoridade da linguagem técnica e educação universitária, a medicina transformou-se em atividade reservada aos homens, já que nesta época apenas eles poderiam ter acesso à educação. A situação das parteiras e curandeiras ameaçava o monopólio deste saber. Embora o caça às bruxas não tenha acabado com parteiras e curandeiras, conseguiu transformar sua prática em atividades suspeitas (Ehrenreich \& English,1976 apud Vieira, 2002: 69).

\section{As plantas medicinais de Grisley}

Resultante de uma leitura paleográfica da obra original de Grisley (1656), são apresentadas a seguir as plantas medicinais indicadas para enfermidades e problemas femininos.

A relação das plantas é apresentada com a seguinte organização: 1 A denominação original do autor 
em negrito; 2 Entre colchetes a denominação original de autores clássicos citados pelo autor; 3 A atual identificação das espécies botânicas e 4 Os comentários e indicações do autor sobre as plantas, traduzidos através de uma leitura paleográfica.

1 Artemija [Artemisia] (Artemisia vulgaris L. Asteraceae) O xarope desta erva sara as doenças da madre e a detém em seu próprio lugar, resolve as ventosidades frias e as dores delas; conforta os nervos, abre os poros, purifica o sangue e tanta simpatia tem com ela que retém o mês supérfluo e faz vir o tardio. Muita falta faz o desterro deste remédio tão aprovado contra a esterilidade das mulheres de naturezas frias e úmidas. Para facilitar o conceber tomam desta Artemísia uma onça em pó, da raiz da bistorta meia onça, de noz moscada duas oitavas misturado tudo muito bem com sete onças de açúcar branco; tomandose este pó sobre fatias molhadas pela manhã e a noite, é mezinha experimentada para mulheres estéreis, fazendo juntamente os seus lavatórios com a mesma erva, que conforta as veias e os nervos.

\section{Ditamo de Creta [Dietamnum] (Origanum dictamnus}

\section{Lamiaceae)}

O cozimento ajuda muito a deitar as páries ${ }^{1}$, bebido e aplicado por fora [...] Todos os Autores, assim antigos, como os mais modernos, concordam que só esta erva abranda o parto.

3 Coroa de Rey [Sertula campana, melilotus, trevo cheiroso] (Melilotus officinalis (L.) Pall. Fabaceae)

[...] cura a madre ${ }^{2}$ dura e inchada [...] Cozida com arrobe, cabeças de Dormideiras, Linhaça ou Ervinha pisada, resolve e abranda todos os inchaços da madre e das mais partes ocultas, põe-se morninha.

4 Millefolio [Stratiotes millefolium] (Achillea millefolium

\section{Asteraceae)}

Pisada e tomada com sua própria água destilada estanca o froixo da natureza dos homens e o fluxo albo nas mulheres, principalmente sendo composto com Coral Vermelho, Alambre e Marfim.

1 Paredes da placenta.

2 Útero.
5 Sabina (Juniperus sabina L. Cupressaceae)

As folhas tem grande virtude de purgar as mulheres [...]. O cheiro delas é fortum, e causa grandes dores de cabeça às mulheres prenhes.

6 Saboeira [Struthium, radicola, lanaria erba] (Saponaria officinalis L. Caryophyllaceae)

Ajuda a lançar as páries.

7 Saxifragia [Saxifragia alba] (Saxifraga spp. Saxifragaceae)

Faz vir o mez.

8 Pee de Leam [Alchimilla; Pesleonis vulgaris] (Alchemilla vulgaris L. Rosaceae)

A semente estanca o froixo albo às mulheres, que impede o conceber [...] O cozimento dela com Cavalinha, Rosas vermelhas, Pedra Ume como emplastro, entesa os peitos moles às mulheres. $\mathrm{O}$ pó dela bebido em qualquer caldo uns vinte dias antes facilita o conceber.

9 Estrellada [Allysoon; hepatica stellaris] (Saxifraga stellaris L. Saxifragaceae)

Pisada em modo de emplastro nas partes baixas estanca o froixo às mulheres.

10 Contra Peçonha [Asclepias; Vincetoxicum] (Asclepias vincetoxicum (Swallow-Wort)

Asclepiadaceae)

Purga as mulheres [...] A erva com bonina pisada e posta sobre os peitos inchados logo os abranda.

11 Astrança [Astrancia; Imperatoria] (Astrantia major L. Apiacaea)

O pó da raiz [...] limpa a madre das mulheres frias e fleumáticas, e as faz coradas.

12 Bistorta [Britanica] (Polygonum bistorta L. Polygonaceae)

Com água que estiver cozida esta raiz se lavarão com grande proveito as mulheres prenhes, sujeitas a móvitos ${ }^{4}$; por boa razão nenhuma parteira houvera de estar sem ela.

3 Corrimento branco vaginal (candidíase).

4 abortamento 
13 Macella Fedegoza [Cotula faetita] (Anthemis cotula L. Asteraceae)

O lavatório [da erva] dos pés é muito excelente para mulheres sujeitas às mudanças, movimentos e dores da madre; em tal caso faz tanto a cheirar somente, como o Castóreo em abrandar a madre revoltosa e fazendo-a recolher ao seu lugar.

14 Loureiro de Alexandria [Aurus Alexandrina] (Ruscus aculeatus L. Asparagaceae)

Uma oitava do pó [da raiz] dela bebida em vinho doce ou água de Canela facilita o parto e faz deitar as páries. Tomada em vinho quente sara a insofrível dor da madre.

\section{Levistico [Ligusticum] (Ligusticum officinale (Makino)} Kitag. Apiaceae)

As folhas, a raiz e a semente, tomadas por dentro ou usadas em lavatório, esquentam o corpo das mulheres frias, purgam e faz deitar as páries, [...]. Faz inchar as pernas das mulheres prenhes.

16 Endro Bravo [Meum Athamanticum; Anethum sylvestre] (Anethum graveolens $\mathrm{L}$. Apiaceae)

A raiz é aprovada mezinha para mulheres velhas e resfriadas, sujeitas às relíquias dos achaques da madre.

\section{Linaria [Osyris] (Linaria sp. Plantaginaceae)}

O sumo posto com panos no rosto de noite, tira todas as suas nódoas, acertado remédio para as mulheres que desejam ter um bom carão.

18 Saramunda [Sanamunda; Radix benedicta; Chrysogonum] (Geum urbanum L. Rosaceae)

O cozimento [da raiz] sara cólica, assim do frio e ventosidade, como de madre.

19 Consolda Maior [Symphitum; consolida maior; confrei] (Symphytum officinale L. Boraginaceae)

$O$ pó das folhas secas tomado em vinho vermelho estanca o fluxo das mulheres.

20 Athanasia [Tanacetum, no Brasil: catinga-de-mulata] (Tanacetum vulgare L. Asteraceae).

Purga as mulheres. Faz deitar as páries e a criança que estiver já morta no ventre, sem moléstia alguma. Sara todos os inchaços e inflamação do membro da mulher com chagas, ou sem elas, desopila as veias da urina. O sumo tomado com mirra tem grande eficácia para tais afecções.

21 Unha de Cavalo [Tussilago; Ungula Caballina] (Tussilago farfara L. Asteraceae)

As parteiras cozem esta raiz em água com a qual misturam depois um pouco de mel para a fazerem doce e a dão a beber à mulher que tiver a criança morta no ventre, para a deitar sem moléstia.

22 Veronica (Veronica officinalis L. Scrophulariaceae) O seu cozimento consome a fleuma ${ }^{5}$ da madre.

23 Acoro [Acoro Calamus Aromaticus] (Acorus calamus L. Acoraceae)

[...] purga as mulheres, desopila as veias da madre valentemente $[\ldots]$

24 Árvore de Castidade [Agnus Castus; Vitex] (Vitex agnus-castus L. Verbenaceae)

Purga as mulheres. O cozimento das folhas e sementes como lavatório abranda os achaques da madre.

25 Alho [Allium] (Allium sativum L. Liliaceae)

Purga as mulheres e faz deitar as páries [...] O sumo de alho queimado tomado por baixo, faz vir a conjunção das mulheres. A cinza do alho queimado por si só cura as velhas; as mulheres que estão pelo acidente da madre no desmaio $[\ldots]$

26 Malvaisco [Althaea] (Althaea officinalis L.Malvaceae). A raiz desfaz os peitos inchados das mulheres.

\section{Ammi (Ammi majus L. Apiaceae)}

Purga as mulheres. Uma meia oitava [da raiz] pisada e bebida com água de flor é certo remédio para a cólica fria e dores da madre causadas por ventosidades [...]

28 Endro [Anetum] (Anethum graveolens L. Apiaceae) O cozimento da erva e sementes bebido faz tornar a vir o leite das mulheres.

$5 \mathrm{Na}$ medicina antiga, humor corporal supostamente causador de indolência e apatia. 
29 Angelica (Angelica archangelica L. Apiaceae)

O cozimento por dentro e as folhas, raiz e Arruda com mel por fora $[. .$.$] faz deitar as páries, purgam as mulheres [\ldots]$

30 Erva Doce [Anisum] (Pimpinella anisum L. Apiaceae) Purga as mulheres $[\ldots]$ aumenta às amas de leite $[\ldots]$

31 Salça [Apium Sativum] (Petroselinum sativum Hoffm. Apiaceae)

No comer purga pela urina e as mulheres pelo costume. É de grande proveito às paridas no caldo de galinha. $\mathrm{O}$ cozimento dela com mel apurado é remédio certo para as tortas depois do parto [...]

31 Estrelamim [Aristolochia longa] (Aristolochia longa L. Aristolochiaceae)

O pó dela misturado com Mirra e Pimenta purga as mulheres e limpa a madre.

\section{Jaro [Aron] (Arum maculatum L. Araceae)}

Duas oitavas tomadas em vinho fazem urinar e purgam as mulheres pelo costume [...] Com o sumo desta raiz, untado o membro a qualquer fêmea vivente em tempo de parir facilita o parto. Para as mulheres que desejam ser formosas se faz desta raiz um mui afamado pó chamado Gersum serpentarium e com ele o Unguento Citrino, que abranda, limpa e faz a carne macia e mui alva.

33 Asaro [Asaru] (Asarum europaeum L. Aristolochiaceae) O sumo dela [...] abranda os peitos inchados das mulheres paridas. O cheiro dela provoca o sono; desopila, purga as mulheres e faz urinar.

\section{Betonica (Betonica officinalis L. Lamiaceae)}

Faz conceber facilmente as mulheres frias e estéreis.

35 Bolça de Pastor [Bursa pastoris] (Capsella bursapastoris L. Brassicaceae)

O sumo cozido com um pouco de Bolo Armênio e folhas de Tanchagem estanca [...] o fluxo da mulheres.

\section{Neveda [Calamintha] (Clinopodium nepeta (L.)} Kuntze. Lamiaceae)

O sumo bebido com vinho [...] abranda as dores da madre e purga as mulheres.
37 Maravilha [Calendula; Caltha] (Calendula sp. Asteraceae)

A bonina ${ }^{6}$ com vinho faz purgar as mulheres com muita eficácia [...] Tomado o sumo dela por baixo faz deitar as páries com muita facilidade. As folhas secas no forno e tomadas pela boca saram o fluxo das mulheres.

38 Cravo Romano [Caryophylus Montano; Latifolius flore globoso maior; Statice] (Armeria pseudoarmeria (Murray) Mansf. Plumbaginaceae)

O cozimento dela com vinho e mel tomado por baixo [...] estanca o fluxo das mulheres.

39 Fel da Terra [Centaureum minus] (Centaurium erythraea (Griseb.) Wight. Gentianaceae)

Feita uma mecha de lã cardada molhada no sumo dela, atrai para si as páries.

40 Macella Galega [Chamaemelum; Anthemis] (Achyrocline satureioides (Lam.) DC. Asteraceae.

O cozimento da raiz, folhas e boninas, misturado no beber, ou usado em modo de banho, esquenta e conforta a madre, tira a criança morta, purga as mulheres [...]

41 Celidonia [Chelidonium maius] (Chelidonium majus L. Papaveraceae)

Posto um emplastro sobre o umbigo feito de Celidonia e azeite, sara a cólica e a dor da madre. Posta esta erva sobre o peito, estanca o fluxo das mulheres [...]

42 Goivo Amarello [Cheiri, Leucoio, Luteum] (Erysimum cheiri (L.) Crantz. Brassicaceae)

A semente bebida com vinho, purga as mulheres e tira as páries.

43 Almeirão [Cichoriu; Seris, Intybus, chicória] (Cichorium intybus L. Asteraceae).

A água em que estiver cozido o Almeirão, bebida tem particular virtude de purgar as mulheres, o que é para notar.

44 Taveda [Coniza maior]

O cozimento das folhas e boninas purga as mulheres e tem mais vigor se for a metade no vinho [...] O cozimento

6 botões florais 
dela só em água sara todos as achaques do membro das mulheres.

45 Pepino de S. Gregório [Cucumis sylvestris] (Ecballium elaterium (L.) A. Rich. Cucurbitaceae)

As papas de farinha de favas misturadas com o sumo desta raiz, limpam o rosto, tiram sardas e o pano; fazem as mãos alvas; é remédio mui fácil para as que desejam parecer formosas.

46 Cuminho [Cuminum sativum] (Cuminum cyminum L. Apiaceae)

[...] sara a cólica e as dores da madre.

47 Daucus [Daucus creticus] (Athamanta cretenses L. Apiaceae)

A semente de qualquer modo tomada no corpo, purga as mulheres, facilita o parto e faz urinar [...]

48 Cinoira [Daucus radice nigra; Pastinaca sativa] (Daucus carota L. Apiaceae]

Esta raiz $[. .$.$] convém bem às mulheres prenhes.$

\section{Fava [Faba] (Vicia faba ( L.) Fabaceae)}

Em favor das moças, que de ocupadas não tem tempo, nem ocasião para se enfeitarem depressa: ponham favas em vinagre bem forte, até que se abra a casca, a qual tirada e as favas secas ao sol e depois pisadas em pó, delas façam um polme com água de chafariz e quando se quiserem deitar de noite na cama, untem-no no rosto, e no outro dia o terão macio, alvo e claro.

50 Filipendula [Onanthe] (Filipendula ulmaria (L.) Maxim. Rosaceae)

A raiz e as folhas cozidas em água e mel e bebido, ajuda grandemente ao parto e faz deitar as páries.

51 Funcho [Foeniculo] (Foeniculum vulgare Mill. Apiaceae)

As folhas cozidas em vinho branco, acrescentam muito leite às amas, e é bom que se misturem em todas as comidas raiz de Funcho. Se a mulher que cria tiver falta de leite, que corra a criança risco, tome semente de Funcho meia onça, semente de Alface, de Salsa, de Endro e de Erva doce, de cada coisa uma oitava, feito em pó fino, beba dele todas as manhãs em vinho branco, e criará muito leite e pode e pode por as folhas na água que beber cada dia.

52 Ervinha [Foenu Graeco] (Trigonella foenum-graecum L. Fabaceae)

Assentando-se uma mulher sobre estas sementes quentes, depois de bem cozidas, sara em breve se tiver a madre inchada.

53 Eleboro Negro [Heleborus; Veratrum nigrum] (Helleborus niger L. Ranunculaceae)

Usada por baixo purga as mulheres.

54 Cevada [Hordeum] (Hordeum vulgare L. Poaceae)

Cozida com Funcho faz tornar a vir o leite das mulheres.

55 Isope [Hysopum] (Hyssopus officinalis L. Lamiaceae) Tomado o cozimento por baixo, limpa a madre, faz urinar e purga as mulheres.

56 Alfazema [Lavendola] (Lavandula officinalis Chaix \& Kitt. Lamiaceae)

O cozimento bebido [...] limpa a madre da fleuma viscosa pela urina e faz hábil para conceber.

57 Cebolla Cessem [Lillium álbum] (Crinum erubescens Aiton. Amaryllidaceae)

A raiz e as folhas cozidas no vinho purgam as mulheres.

58 Peroleira [Lithospermon; Milium Solis](Lithospermum officinale L. Boraginaceae)

Tomando uma mulher na hora de parir duas oitavas do pó desta semente, com leite de peito, facilita em grande maneira o parto.

59 Luparo [Lupulus] (Humulus lupulus L. Cannabaceae) $\mathrm{O}$ vapor das boninas cozidas, abranda a madre dura e cerrada $[\ldots]$

60 Malva (Malva sylvestris L. Malvaceae)

O cozimento das Malvas, Funcho e Erva doce faz criar muito leite às amas. Dando a uma mulher, para parir, muitas vezes o caldo da Malva muito bem cozido, raiz e folhas, facilita muito o parto. 
61 Matricaria [Parthenium] (Tanacetum parthenium (L.) Sch. Bip. Asteraceae)

O cozimento dela abre a madre desopilando e apaga a inflamação e sara as inchações dela. Pisada como emplastro e posta abaixo do umbigo ajuda muito na conjunção das mulheres.

62 Alipivre [Melanthium; Semen nigelae] (Nigella sativa L. Ranunculaceae)

Esta semente bebida alguns dias em vinho, faz urinar, purga as mulheres, mata lombrigas e faz crescer o leite das amas, limpa o peito e sara a cólica. Bebida com águas apropriadas é contra a peçonha, desfaz as ventosidades e sara os achaques do estômago e da madre.

63 Erva Cidreira [Melissa; Apiastrum] (Melissa officinalis L. Lamiaceae).

O cozimento purga as mulheres, lavando o corpo com ele [...] O cheiro abranda a dor e conserta a madre e melhor bebendo o cozimento dele [...] Os lançamentos novos fritos em manteiga com ovos e comidos com açúcar com água rosada, é agradável e saudável para as paridas, pelo afeito que faz.

64 Ortelã [Mentha] (Mentha spicata L. Lamiaceae). Bebendo um bom trago do cozimento desta erva na hora de parir, facilita muito o parto [...] A semente pisada [...] posta sobre os peitos abranda a sua dureza causada por muito leite.

65 Mentrasto [Menthastrum] (Ageratum conyzoides L. Asteraceae)

O cozimento por dentro e por fora esquenta madre fria e abranda os puxos.

66 Murta [Myrtus] (Blepharocalyx salicifolius (Kunth) O. Berg; Myrtaceae)

Lavando-se e assentando-se no cozimento das folhas e frutos, conforta a madre, torna a por em seu lugar e a enxuga.

67 Mastruço [Nasturtium] (Nasturtium officinale R. Br. Brassicaceae)

A semente pisada tomada em água apropriada [...] ajuda a deitar a criança morta no ventre.
68 Golfão [Nimphaea; Nenuphar] (Nymphaea alba L. Nymphaeaceae)

A raiz e a semente bebidas em águas convenientes, estancam a demasiada purgação das mulheres.

69 Majericão [Ocymum] (Ocimum basilicum L. Lamiaceae)

O seu cozimento [...] purga as mulheres, faz urinar, limpa e conforta a madre [...] Pisada e posta sobre os peitos resolve o leite coalhado neles de frio [...] a semente, tomada por dentro, seca o leite; o sumo, tomado por fora, tira a criança morta.

70 Salsa de Cavallos [Olus atrum; Hipposelinum] (Smyrnium olusatrum L. Apiaceae)

A semente [...] purga as mulheres e faz deitar as páries.

71 Papoilas [Papaver erraticum] (Papaver somniferum L. Papaveraceae)

Panos molhados [no cozimento das boninas pisadas] estanca o fluxo das mulheres [...] gargarejando com ela, cura as chagas podres do membro, assim dos homens, quanto das mulheres.

72 Pionia [Paeonia] (Paeonia officinalis L. Ranunculaceae) Dá-se do tamanho de uma castanha às paridas para purgarem bem [...] bebida com vinho abranda as dores da madre.

73 Brinça [Peucedanum] (Peucedanum officinale L. Apiaceae)

O sumo feito com águas apropriadas facilita muito o parto.

74 Orelha de Lebre [Pilosella] (Stachys byzantina K.Koch. Lamiaceae).

Cozida e bebida estanca as câmaras de sangue e o fluxo das mulheres.

75 Tanchagem [Plantago] (Plantago major L. Plantaginaceae)

O sumo usado na comida ou bebida estanca o fluxo das mulheres [...] Nas dores da madre mete-se no corpo uma mecha ensopada no sumo, ainda que seja na conjunção do mês. 
76 Sempre Noiva [Polygonium] (Polygonum aviculare L. Polygonaceae).

Bebido com vinho estanca o fluxo das mulheres [...]

77 Erva Andorinha [Polygonum niveum; Lobelij] (Chelidonium majus L. Papaveraceae)

[...] purga as mulheres. Misturado com vinho e um pouco de mel o cozimento desta erva usado como lavatório e posto com panos [...] sara todos os achaques do membro do homem e da mulher.

78 Erva Ferro [Prunella; Consolida media] (Prunella vulgaris L. Lamiaceae)

O cozimento sara as chagas do membro dos homens e mulheres.

79 Abrunhos [Pruna silvestria] (Prunus spinosa L. Rosaceae)

[...] a quem tem a madre fora [...] se assentará num cozimento feito de Abrunhos e da casca da raiz do Abrunheiro, com água dos ferreiros e confortará a madre no seu lugar.[...] o sumo estanca o fluxo das mulheres [...]

80 Zaragatoa [Psillium] (Plantago psyllium L. Plantaginaceae)

Uma oitava das sementes bebida com água mel, ajuda a purgar as mulheres $[\ldots]$

81 Poejos [Pulegium] (Mentha pulegium L. Lamiaceae) O cozimento purga as mulheres, facilita o parto e tira as páries $[\ldots]$

82 Rapontis [Rhaponticum] (Rhaponticum carthamoides (Willd.) Iljin. Asteraceae)

[...] abranda a cólica e as dores da madre.

83 Solda [Rubia tinctorum maior] (Rubia tinctorum L. Rubiaceae)

O cozimento dela misturado com uma confeição da botica chamada Triphera magna e bebido, estanca o fluxo das mulheres $[\ldots]$

\section{Arruda [Ruta] (Ruta graveolens L. Rutaceae)}

Misturada com mel e untada no ventre em baixo sara as dores da madre [...] Arruda e bagas de Louro pisadas e usadas como emplastro, sara as inchações do membro do homem e da mulher.

\section{Salva [Salvia] (Salvia officinalis L. Lamiaceae)}

Cozida em vinho e bebida, purga as mulheres, faz urinar e enxuga a madre [...] Remédio experimentado para as mulheres estéreis.

86 Segurelha [Saturela] (Satureja montana L. Lamiaceae) Não convém às prenhes [...] Esta erva é de grande proveito às paridas, cozida no caldo de galinha, as faz purgar, não causam dor como nas prenhes, nem deixa criar ventosidades, antes tira as que acham.

87 Douradinha [Scolopendrium; Seteraes; Asplenum] (Asplenium scolopendrium L. Apleniaceae)

Faz as mulheres estéreis.

88 Enceyão [Sedum majus] (Sedum majus (Hemsley) Migo, Crassulaceae)

Estanca o fluxo das mulheres.

89 Uva de Cão [Semper vivum; Vermicularis] (Tamus communis (L.) Dioscoreaceae)

Pisada como emplastro sara [...] os achaques do peito das mulheres.

90 Serpilho [Serpillium] (Thymus serpyllum L. Lamiaceae)

O cozimento bebido ajuda a purgar as mulheres, faz urinar, sara a cólica $[\ldots]$

91 Mostarda [Sinapi] (Sinapis alba L. Brassicaceae) O cheiro só da farinha misturada com vinagre forte, torna a revoltosa madre a seu lugar.

92 Erva Moura [Solanum] (Solanum nigrum L. Solanaceae)

Uma mecha molhada no sumo de folhas pisadas, com um pouco de sal, estanca o fluxo das mulheres.

93 Raiz Mordida [Succsisa] (Succisa pratensis Moench. Caprifoliaceae)

A raiz só de per si comida, ou cosida em vinho, e bebido, abranda a cruel dor da madre revoltosa. 
94 Sumagre [Sumach; Rhus obsoniorum] (Rhus coriaria

L. Anacardiaceae)

Estanca o fluxo das mulheres [...]

95 Tamarigueira [Tamariscus; Myrica] (Tamarix africana Poir. Tamaricaceae)

O cozimento estanca [...] o fluxo das mulheres [...] O vapor do cozimento cura as mulheres achacosas de fluxo alvo.

96 Tumilha [Thymus] (Thymus vulgaris L. Lamiaceae) $\mathrm{O}$ cozimento [...] purga as mulheres, tira as páries e faz urinar.

97 Tormentina [Tormentilla] (Potentilla erecta (L.) Raeusch. Rosaceae)

A raiz cosida em vinho e bebida conforta o ventre da mulher prenhe. $\mathrm{O}$ vapor da raiz cosida em água da chuva tomado por baixo e o pó dela misturado com mel como emplastro, posto sobre o ventre, conforta o fruto concebido e defende o movimento.

98 Birliana [Valeriana] (Valeriana officinalis L. Valerianaceae)

$[\ldots]$ purga as mulheres [...] entra com proveito no lavatório para mulheres estéreis.[...] O vapor do cozimento enxuga a madre, o mesmo faz o pó da raiz, usado com mechas.

99 Barbasco [Verbascum; Tapsus barbatus] (Verbascum thapsus L. Scrophulariaceae)

O emplastro feito das boninas, folhas pisadas com uma gema de ovo e Cevada, estanca o fluxo das mulheres.

100 Urgebão [Verbena; Erva sacra] (Verbena officinalis L. Verbenaceae)

O cozimento [...] sara a cólica e as dores do ventre [...] purga as mulheres.

101 Congossa [Vinca pervinca maior; Clematis] (Vinca major L. Apocynaceae)

O sumo bebido com vinho ou água apropriada [...] cura o fluxo das mulheres. Cozida no leite e óleo rosado e usada como mecha, abranda as dores da madre.

\section{Aspectos Conclusivos}

Das 260 plantas medicinais referenciadas por Grisley (1656) em sua obra (distribuídas em três "canteiros" ou capítulos, sendo 20 no primeiro, 40 no segundo e 200 no terceiro). Desse total, 101 plantas medicinais são indicadas para mulheres, apenas quatro são indicadas para o uso cosmético ("Linaria", "Jaro", "Pepino de S. Gregório" e "Fava") e 97 para terapêutica da reprodução feminina, com ênfase aos problemas (ou "achaques") uterinos.

Embora não se refira diretamente à "sufocação da madre", Grisley menciona os seus deslocamentos quando trata das plantas: "Macella Fedegoza", "Murta", "Abrunhos" e "Mostarda".

$\mathrm{Na}$ verdade, suas plantas medicinais não são descritas exclusivamentepara a terapêutica de enfermidades femininas, servem, segundo o autor, para muitas outras enfermidades comuns das pessoas. Entretanto, na obra, quando as mulheres são citadas, quase sempre, o autor se refere a um problema do aparelho reprodutor feminino ("madre", "páries", mamas, leite materno, fluxo uterino, menstruação, "móvito", aborto, purgas, cólicas, dores uterinas, esterilidade, prenhez, parto, etc). Isto significa que as referências de Grisley estão no contexto do que Souza (2012: 130) denomina, com propriedade, de "úterocentrismo". Nessa perspectiva, o corpo feminino estaria destinado exclusivamente a procriação.

Curiosamente, em toda obra, só uma única vez o autor se refere a presença de uma parteira na assistência ao parto, quando se refere ao uso de uma planta denominada "Bistorta", escreve que "por boa razão nenhuma parteira houvera de estar sem ela".

Como escreve Vieira (2002: 69), a produção de ideias médicas sobre o corpo feminino não se fez de forma teórica e isolada da tomada deste corpo como objeto da prática médica. Por quase três séculos, os médicos se prepararam para ocupar o lugar das parteiras e efetivamente transformar o parto em um evento médico.

Entretanto, entre os herbários e farmacopeias dos séculos XVII e XVIII, a obra de Grisley, apresenta uma ênfase especial nas enfermidades do corpo feminino, nos problemas e enfermidades do sistema reprodutor, constituindo $39 \%$ das plantas medicinais referenciadas na obra. 
Muitas das plantas referenciados pelo autor, há muito estão aclimatadas no Brasil e são comumente usadas pela fitoterapia popular brasileira.

O arqueólogo australiano Gordon Childe (18811957) foi um dos primeiros estudiosos do período neolítico, que chamou a atenção na participação prioritária das mulheres no desenvolvimento de cultivos vegetais durante a pré-história (Childe, 1981: 91).

Sob uma perspectiva materialista, a intelectual soviética Alexandra Kollontai, no início do século passado, ao estudar as sociedades primitivas da "préhistória", escreve que, existem evidências que as mulheres das tribos dedicadas ao cultivo da terra gozavam de muito maior igualdade com os homens. Algumas tribos camponesas mesmo possuíam um sistema matriarcal. No entanto, o patriarcado, ou seja, a predominância do direito paterno (detinha o poder o membro mais antigo da tribo) foi desenvolvido em povos pastoris, nômades (Kollontai, 1976: 3).

Por que foi assim? O motivo foi, naturalmente, o papel das mulheres na economia. Em povos agrícolas a mulher foi a primeira produtora. Há provas abundantes de que a mulher foi quem inaugurou pela primeira vez a ideia de cultivar a terra, foi a primeira que trabalhou na agricultura (Kollontai, 1976: 4).

Possivelmente, a mulher chegou à ideia da agricultura da seguinte maneira: mães com filhos lactantes não poderiam participar diretamente das atividades da caça, porque eram incapazes de seguir os passos das expedições, além do que as crianças também dificultavam as operações venatórias. Portanto, a mãe ficava com seu filho e era obrigada a esperar até que a tribo voltasse da caça. Não era simples obter comida e muitas vezes a espera era muito longa. Ela não dispunha de muitas provisões e, portanto, foi forçada a obtê-las com seu próprio esforço para seu alimento e o da criança. Por isso os cientistas deduziram que é muito provável que a mulher começou a cultivar a terra. Quando as provisões de frutos esgotavam no local que ela esperava o retorno da tribo, ela teve que procurar plantas com sementes comestíveis, para comê-las e também alimentar seu filho. Enquanto triturava os grãos entre os dentes, alguns destes caiam ao chão e quando depois de algum tempo a mulher voltava ao mesmo lugar, descobriu que os grãos caídos ao solo e tinham começado a germinar e ela marcou esses lugares. E então ela se deu conta de que era uma vantagem voltar quando a planta estava madura: a busca de alimentos custaria menos esforço. Assim, os seres humanos aprenderam com a experiência que os grãos que caiam no chão começavam a crescer. E com base na experiência, elas também perceberam que a colheita era melhor quando a terra era revolvida anteriormente. Com o tempo a tribo descobriu que as crianças morreriam de fome, quando não se retornava ao "lugar das ervas", finalmente, começou a observar estritamente este costume e a acreditar na "sabedoria" das mulheres. Como a mulher estava interessada obter o máximo desempenho com o mínimo esforço, constatou o seguinte: quanto mais poroso o solo, melhor seria o plantio, melhor a colheita. A mulher plantava, agachada ao chão, arranhando os campos da terra com a ajuda de enxadas de pedra ou forcados. Ela iria mostrar que desta forma os seres humanos teriam mais segurança do que vagando pela floresta em busca de frutas, com o perigo constante de serem dilacerados por animais de presa (Kollontai, 1976: 4-5).

Por causa de sua maternidade tinha as mulheres entre os membros da tribo, uma situação especial. A ela deve a humanidade a descoberta da agricultura, uma nova força que fez avançar significativamente seu desenvolvimento economico. Foi esta descoberta tanto tempo determinado o papel da mulher na sociedade e na economia e colocado no topo dessas tribos que foram dedicadas ao cultivo da terra. Elas colhiam ervas e sabiam suas propriedades medicinais; nossas mães primitivas foram as primeiras médicas (Kollontai, 1976: 5).

Sob uma ótica mítica, a antropóloga Rosalira Oliveira (2005), escreve que, o culto do divino feminino é um dos mais antigos que se tem notícia. $\mathrm{O}$ primeiro elemento cultuado pelo homem foi a Terra. E a Terra, dizem os mitos, foi gerada por ela mesma. Era ela que produzia os frutos, os animais e o próprio homem. Ela era a mãe de todas as coisas vivas e também a responsável pela morte. Afinal, se a vida era percebida como um $a b$ uterum, um emergir do seu ventre, a morte representava uma volta, um regresso ad uterum, para que um novo nascimento pudesse acontecer. Assim ocorria com as sementes, assim também com os homens. Os ciclos de morte e renascimento; criação e destruição; observados na natureza, eram sentidos como igualmente válidos para a trajetória do homem no mundo. Para a humanidade do 
início dos tempos, não havia separação entre o mundo humano e o mundo natural e todos compartilhavam o mesmo destino como filhos da Terra. É exatamente em respeito a esse vínculo que a arqueóloga Marija Gimbutas, considera importante esclarecer que "a Deusa era a Mãe mais-do-que-humana. Se for usado o termo Grande Mãe, deve ser entendido como a Grande Mãe Universal cujos poderes se difundem por toda a natureza, por toda a vida humana, por todo o mundo animal, por toda a vegetação" (Gimbutas, 1998 apud Oliveira, 2005: 1).

Os estudiosos costumam situar as origens do culto da Deusa no período Paleolítico (por volta de 100.000 a 10.000 a.C.), também chamado "período dos caçadores/coletores". As estátuas da Deusa representada como uma mulher com seios e nádegas pronunciadas - as chamadas "Vênus Paleolíticas" - estão entre as primeiras representações do divino que a humanidade elaborou. Algumas dessas imagens datam de 30.000 anos atrás. Tradicionalmente vistas como ligadas a algum culto antigo de fertilidade, elas foram reinterpretadas por Marija Gimbutas como representações dos poderes do mundo geradores da vida, precursoras muito antigas da GrandeMãe que ainda será reverenciada em épocas históricas. No seu entendimento, as imagens das "Vênus", com suas características femininas - seios, ventre, vulva, quadris - deliberadamente exageradas seriam representações da Grande-Mãe (Oliveira, 2005: 3).

A Grande Mãe do Paleolítico atravessa toda a chamada "revolução agrícola" para firmar, no período seguinte, sua adoração. O Neolítico é considerado um momento de grande prestígio do feminino, fato atestado pelo impressionante número de esculturas, gravuras e outras imagens representando imponentes personagens femininos, cujo poder e natureza divina se afirmam nitidamente. É ainda Marija Gimbutas quem percebe nesta continuidade da representação feminina, "uma única linha de desenvolvimento de um sistema religioso, desde o Paleolítico Superior, passando pelo Neolítico, pelo Calcolítico e pela Idade do Cobre baseado em uma organização matrifocal" (Ginbutas, 1998 apud Oliveira, 2005: 3).

A adoração da Deusa e matrifocalidade parecem caminhar juntas, caracterizado pelo surgimento da agricultura, o período Neolítico marca um momento de extrema valorização dos aspectos positivos da Grande-
Deusa como deusa da fecundidade, criadora da vida e também da mulher vista como a criadora no âmbito do humano (Oliveira, 2005: 3).

Mesmo levando-se em consideração o fato de que a concepção da sacralidade da maternidade e da mulher já se fazia presente desde o período anterior, pode-se inferir que a descoberta da agricultura reforçou consideravelmente essa associação vinculando simbolicamente a fertilidade da terra à fecundidade feminina (Oliveira, 2005: 3).

Escreve Eliade sobre isso:

A mulher relaciona-se, pois, misticamente com a Terra; o dar à luz é uma variante, em escala humana, da fertilidade telúrica. Todas as experiências religiosas relacionadas com a fecundidade e o nascimento têm uma estrutura cósmica. A sacralidade da mulher depende da santidade da Terra.Afecundidade feminina tem um Modelo cósmico: o da Terra Mater, da Mãe universal. Em algumas religiões acredita se que a Terra Mãe é capaz de conceber sozinha, sem o auxílio de um companheiro. [...] A tais concepções míticas correspondem as crenças relativas à fecundidade espontânea da mulher e a seus poderes mágico religiosos ocultos, que exercem uma influência decisiva na vida das plantas. O fenômeno social e cultural conhecido como matriarcado está ligado à descoberta da agricultura pela mulher. Foi a mulher a primeira a cultivar as plantas alimentares. Foi ela que, naturalmente, se tornou proprietária do solo e das colheitas. O prestígio mágico religioso e, consequentemente, o predomínio social da mulher têm um modelo cósmico: a figura da Terra Mãe (Eliade, 1992: 71-72, grifos nossos).

A solidariedade dos mortos - enterrados como as sementes - com a fertilidade e a agricultura reforça a onipotência da Terra-Mãe e, com ela, o prestígio das mulheres. A própria atividade agrícola é uma prática regenerativa. Através dela a semente enterrada sob a terra volta à vida. É por conta dessa afinidade, e da natureza ctônica de ambos, que os cultos da fertilidade vinculamse, de modo profundo, aos cultos mortuários. Neste complexo simbólico, tudo que toca à vida e, portanto, à riqueza, diz respeito à mulher. Fonte da fertilidade ela é também a curadora que conhece as ervas e a protetora que guarda o sono dos mortos até que estejam prontos para retornarem (Oliveira, 2005: 4). 
Ainda que não restem grandes dúvidas sobre a organização social pacífica e sobre o prestígio desfrutado pela mulher neste período - seja como responsável pela fertilidade do grupo, pelas curas medicinais ou pelos ritos funerários - muito se discute a respeito do seu real poder político. Alguns estudiosos julgam que o papel de destaque ocupado pela mulher na vida religiosa não implica numa posição semelhante na esfera civil. Para eles, a expressão "ela reina, mas não governa" constitui uma síntese adequada do status da mulher nas sociedades do Neolítico. Já outros se concentram na preponderância da Deusa-Mãe sobre os demais deuses e na reverência ao feminino na criação da vida e chegam a utilizar o termo "matriarcado" para caracterizar estas sociedades. A hipótese de um "matriarcado primitivo", que antecederia as sociedades históricas patriarcais, foi exposta no século XIX por Johann Jakob Bachofen. Sua teoria que inicialmente teve grande aceitação caiu em descrédito já nos primórdios do século XX. No centro dessa discussão, parece haver uma espécie de confusão semântica: enquanto o termo "matriarcado" diz respeito a um "governo feito pelas mães", os termos "matrifocal" e "matricêntrico" referemse à ideia de uma sociedade centralizada na mulher, mas não obrigatoriamente governada por ela. Já o termo "patriarcado" significa literalmente "governo feito pelos pais" (Oliveira, 2005: 4).

As sociedades do período Neolítico eram matrifocais, nas quais o pensamento e as práticas espirituais giravam em torno de uma Deusa-Mãe e onde a filiação era definida através da linhagem materna. A Deusa era uma realidade cósmica. Uma realidade que, ao reificar a ligação entre todo o mundo vivo e sacralizar o mistério da criação, tendia a enfatizar valores, como a cooperação e a convivência pacífica - seja entre os sexos, seja entre o homem e os demais seres, etc. - em detrimento de outros, como a dominação e força bruta. Tratava-se de um mundo matricêntrico muito diferente das sociedades masculinizadas que lhe sucederam (Oliveira, 2005: 5).

Muito tempo depois, durante a Idade Média ocorreu a exclusão das mulheres do meio universitário e de uma desqualificação dos saberes e práticas femininas, ainda que elas se utilizassem das mesmas plantas medicinais, que seriam contempladas nos tratados médicos feitos pelos homens. Mas existiram duas exceções: Trótula de Salerno (princípio do século XI-1097) e a Abadesa
Hildegarda de Bingen (1098-1179). Sendo a primeira, durante a Idade Média, uma autoridade, reconhecida inclusive pelos médicos eruditos da época, em medicina feminina. Suas obras: Liber de sinthomatibus mulierum e Passionibus mulierum curandorum, do século XII, forma parte de um conjunto de tratados médicos medievais que recomendavam o uso de afrodisíacos.

No Brasil, atuais pesquisas etnobotânicas ou antropológicas, entre as populações locais (também chamadas de "comunidades tradicionais"), são unânimes em referenciar a supremacia dos saberes femininos em relação às plantas medicinais. Desde comunidades indígenas ou ribeirinhas da Amazônia (Freitas \& Fernandes, 2006: 57) até agricultores do Rio Grande do Sul (Badke et al., 2012: 366 e Ceolin et al., 2011: 49), passando por quilombolas (Franco \& Barros, 2006: 81) e camponeses do Nordeste (Freitas et al., 2012: 55) e do Centro Oeste (Viu et al., 2010: 145), caiçaras do Sudeste (Borges \& Peixoto, 2009: 775). São as mulheres as responsáveis transmissão e aplicação dos saberes sobre o uso de plantas medicinais, sejam elas nativas ou exóticas. Tal conhecimento é repassado de uma geração para outra através da informação oral e de práticas de cura, dentro das famílias.

Diante disso, pode-se dizer que Grisley teria muito pouco a ensinar (ou "desenganar") às mulheres da época, sobre os usos de plantas medicinais. Nada que elas já não soubessem e praticassem na cura de suas próprias enfermidades. Embora que, historicamente, como vimos, seus conhecimentos tenham sido sempre desqualificados pela academia.

\section{Referências}

BADKE, Marcio Rossato; BUDÓ, Maria de Lourdes Denardin; ALVIM, Neide Aparecida Titonelli; ZANETTI, Gilberto Dolejal; HEISLER, Elisa Vanessa. (2012). "Saberes e práticas populares de cuidado em saúde com o uso de plantas medicinais. Texto Contexto Enferm., Florianópolis; 21(2): 363-370.

BORGES, Rodrigo; PEIXOTO, Ariane Luna (2009) "Conhecimento e uso de plantas em uma comunidade caiçara do litoral sul do Estado do Rio de Janeiro, Brasil". Acta bot. bras. 23(3): 769-779. 
CAMACARO GÓMEZ, Daisy J. (2007) “Cuerpo de mujer: território delimitado por el discurso médico...." Comunidad y Salud, Aragua, Venezuela, v.5, no 1, pp.26-31.

CARNEIRO, Henrique S. (2002) Amores e sonhos da flora: afrodisíacos e alucinógenos na botânica e na farmácia. São Paulo: Xamã.

CEOLIN, Teila; HECK, Rita Maria; BARBIERI, Rosa Lía; SCHWARTZ, Eda; MUNIZ, Rosani Manfrin; PILLON, Clenio Nailto. (2011) "Plantas medicinais: transmissão do conhecimento nas famílias de agricultores de base ecológica no Sul do RS”. Rev. Esc. Enferm. USP, 45(1):47-54.

CHILDE, Vere Gordon. (1981) A evolução cultural do homem. $5^{\text {a }}$ ed. Zahar Editores, Rio de Janeiro.

ELIADE, Mircea. ( 1992) O sagrado e o profano. São Paulo: Martins Fontes.

FRANCO, E.A.P.; BARROS, R.F.M. (2006) "Uso e diversidade de plantas medicinais no Quilombo Olho D'água dos Pires, Esperantina, Piauí". Botucatu: Rev. Bras. Pl. Med., v.8, n.3, pp.78-88.

FREITAS, Ana Valeria Lacerda; COELHO, Maria de Fatima Barbosa; MAIA, Sandra Sely Silveira; AZEVEDO, Rodrigo Aleixo Brito de. (2012) "Plantas medicinais: um estudo etnobotânico nos quintais do Sítio Cruz, São Miguel, Rio Grande do Norte, Brasil”. R. Bras. Bioci., Porto Alegre, v. 10, n. 1, pp. 48-59.

FREITAS, Jussara Costa de; FERNANDES, Marcus Emanuel Barroncas. (2006) "Use of medicinal plants by the Enfarrusca community in Bragança, Pará”. Bol. Mus. Para. Emilio Goeldi Cienc. Nat., Belém, v. 1, n. 3, pp. 11-26.

DEL PRIORE, Mary. (1993) Ao sul do corpo-condições femininas maternidades e mentalidades no Brasil Colônia. Rio de Janeiro: José Olympio; Brasília, DF: Edunb.

DEL PRIORE, Mary. (1999) "Viagem pelo imaginário do interior feminino". Rev. bras. Hist., São Paulo, v. 19, n. 37, pp. 179-194.
DEL PRIORE, Mary. (2004) História de Mulheres no Brasil. $7^{\mathrm{a}}$. ed. São Paulo: Contexto.

GRISLEY, Gabriel. (1656) Desenganos para a medicina ou botica para todo pay de famílias. Lisboa: Officina de Henrique Valente de Oliveira.

KOLLONTAI, Alexandra. (1976) La mujer en el desarrollo social. Editorial Guadarrama, Barcelona.

OLIVEIRA, Rosalira. (2005) "Em nome da Mãe: o arquétipo da Deusa e sua manifestação nos dias atuais". João Pessoa: Revista Ártemis, n.3, pp.1-16.

SANTOS, Dulce O. Amarante dos. (2013) "Saúde e enfermidades femininas nos escritos médicos (séculos XIII e XIV)". Cuiabá: Revista Territórios \& Fronteiras, vol. 6, n. 2, pp.7-20.

SOUZA, Lidiane Alves de. (2011) "Incompleto e imperfeito: as representações do corpo feminino nas obras médicas do século XIII". Porto Alegre: AEDOS, v. 3, n. 9, pp.130-138.

STIGGER, Verônica. (2016) "Útero errante". Revista Palavra, n.6, pp.12-16.

VIEIRA, Elisabeth Meloni. (2002) A medicalização do corpo feminino. Rio de Janeiro; FIOCRUZ.

VIU, Alessandra F. M.; VIU, Marco Antônio de O. ; CAMPOS, Letícia Z. (2010) "Etnobotânica: uma questão de gênero?" Revista Brasileira de Agroecologia, Porto Alegre, 5(1): 138-147.

Recebido em: 09/04/2017.

Aceito: 09/07/2017. 